

\section{LA FUNDACIÓN Y EL FUERO UNIVERSITARIO DE LÉRIDA}

por

\section{MARIANO PESET}

Universidad de Valencia.

RESUMEN: En 1297 el pontifice Bonifacio VIII autoriza al rey aragonés Jaime II, la creación de una universidad, que se estableceria en Lérida. Su modelo no sería Toulouse - como quería el pontifice- sino Bolonia, "madre de las leyes" según los fundadores ilerdenses. Su primera documentación, del 1300, permite un buen conocimiento del proyecto, en que colaboraba el rey, el municipio, profesores y escolares. La jurisdicción del estudio se atribuye al rector, de acuerdo con la pauta boloñesa. Su tribunal y competencia, concedida por el rey, se limita por éste, asi como por las autoridades del municipio; no obstante, es amplia, como corresponde a una universidad medieval dominada por los escolares y su rector.

Palabras ClaVE: Historia de las universidades, lérida, edad media, jurisdicción, rector.

ABSTRACT: In 1297 Pope Boniface VIII authorized the King of Aragón James II to cre ate a university which would be set up in Lérida. Its model would not be Toulouse - as the Pope wanted - but Bologna, regarded by the founders as the "mother of the laws». Its first documentation, in 1300, allows us a good knowledge of the project, in which the King, the municipality, professors and students collaborated as well. The jurisdiction of the university was assigned to the Rector, in accordance with the pattern of Bologna. His court and competence, granted by the King, are restricted by the latter as well as by the municipal authorities; nevertbeless, this competence is wide, as is ustual in a medieval university dominated by the students and its Rector.

KEY WORDS: Universities, Lérida, middle ages, jurisdiction, rector.

La creación de la primera universidad de la Corona de Aragón a inicios del XIV nos depara una oportunidad de analizar un estudio general en sus orígenes. Su documentación es abundante, aunque no haya sido recogida en su totalidad.

Hippania, LVIII/2, núm 199 (1998) 515-536 
El esfuerzo de Gaya Massot y de otros ${ }^{1}$ nos brinda amplios materiales, desde donde cabe reconstruir sus primeros años y cómo se estableció la jurisdicción de su rector y la autonomía de la universidad de escolares. Las peninsulares, Salamanca o Lisboa-Coimbra, han alcanzado más suerte en la colección de sus primeros materiales, pero no son éstos tan ticos en datos como los ilerdenses $^{2}$. Mi pretensión en estas páginas se centra en presentar el modelo de su fundación inspirado fuertemente en Bolonia y, dentro del mismo, su autogobierno y su fuero universitario —su jurisdicción, en términos de la época-.

El primero de abril del año 1297 el pontífice Bonifacio VIII, a petición de Jaime II, que quiere fundar un estudio general en alguna ciudad o lugar insigne de su tierra, le confiere licencia para realizarlo ${ }^{3}$. Atendiendo a los frutos que pueden originarse para muchos del estudio y a su laudable propósito, le concede esta autorización indeterminada, que debería gozar de los privilegios, indulgencias, libertades e inmunidades de que está dotado, por la santa sede, el estudio de Toulouse. Nada dice de las facultades que se establecerian, todas,

1 Preparaba su colección RAMÓN GNYA MASSOT, «El Chartularium universitatis ilerdensis", Miscelánea de trabajos sobre el estudio general de Lérida, 3 vols. Lérida, 1949-195, I, págs 9-47, pero no pudo darle fin, por lo que es menester consultar su documentación en España sagrada, t. 47, por PEDRO SAINZ DE BARANDA; J. VILLANUEVA, Viaje literanio a las Iglesias de España, t. 16, Madrid, 1851; H. DENIFLE, «Neue Urkunde zur Universität Lérida», Arcbiv fìr Literatur- und Kirchengescbicbte, 4 (1888), págs. 249-262; H. FINKE, Acta aragonensia: Quellen zur deutschen, italianischen, französischen Kirchen- und Kulturgeschichte, 2 vols. Berlín-Leipzig, 1908; A. RUBIÓ I LLUCH, Documents per l'bistònia de la cultura catalana migeval, 2 vols. Barcelona, 1908-1921, asi como en los diferentes trabajos de Gaya Massot y otros autores que se citan en mis notas. C. M. ${ }^{2}$ AJO, Historia de las universidades bispánicas, I, Madrid, 1957, recoge algunos de estos documentos. Una visión genérica del estudio ilerdense realicé en M. PESET, J. GUTIÉRREZ, "Clérigos y juristas en la baja edad media castellanoleonesa», Senara (Vigo), 3 (1981) Anexo I y en «Interrelaciones entre las universidades españolas y portuguesa en los primetos siglos de su historian, Estudos em homenagem aos profs. doutoures $M$. Paulo Merếa e $G$. Braga da Cruz, en Boletim da faculdade de Direito (Coimbra), 58, 1(1962), págs. 875- 940. Sobre época más tardia, J. LLADONOSA I PUJOL, LEstudi general de Lleida del 7430 al 1524, Barcelona, 1970.

2 Salamanca dispone de la excelente colección de V. BELTRÁN DE HEREDIA, Bulario de la universidad de Salamanca (1219-1549), 3 vols. Salamanca, 1966-1967 y Cartulario de la universidad de Salamanca (1218-1600), 6 vols. Salamanca, 1970-1973. En el primero se recogen las bulas de Palencia, Valladolid y Alcalá de Henares. Lisboa-Coimbra cuenta con la magna colección de A. MOREIRA DE SÁ, Chartularium universitatis portugalensis (1288- 1537), 7 vols. Lisboa, 1966-1978, con Auctarium chartulari universitatis portugalensis, 3 vols. Lisboa, 1973-1979.

3 España sagrada, t. 47, núm. 67, págs. 340-341, recogida en AJO, Historia, I, núm. 28, pág. 452. Se fecha indebidamente en 1300, hasta BOFARULL, Documentos del arcbivo de la corona de Aragón, VI, Barcelona, 1850, doc. 61, págs. 203-204. Hay edición facsímil reciente, transcripción y traducción en 700 aniversari. La universitat de Lleida, Lérida, 1996, págs. 20-21. Responde a una petición de los paers, contestada por Jaime II en $7 \mathrm{de}$ abril de 1293, publicada por P. SANAHUJA, «La enseñanza de la teología en Lérida. Cátedras regentadas por maestros franciscanos (siglos XIV y XV)n, Archivas Iberoamericanos, 38 (1935), págs. 418-448; 2. 'época 1 (1941), págs. 270-298.

Hispania, LVIII/2, núm. 199 (1998) 515-536 
menos teología que se reservaba a París ${ }^{4}$. ¿Qué significaba la indicación de aquella universidad del sur de Francia para la futura Lérida?

\section{EL MODELO DE TOULOUSE}

¿Por qué el pontífice había señalado aquella universidad y no otras más prestigiosas, como Bolonia, París o la más cercana de Montpellier? ¿Por qué no Nápoles; creación del emperador Federico II en 1224 o la propia Salamanca? ¿Qué virtualidad tenía Toulouse para proponerla como modelo frente a las demás? Es este un punto que conviene precisar, antes de ocuparme del modelo ilerdense...

Toulouse habia sido el centro de la herejía albigense, destruida por el papa Honorio III y el rey Felipe Augusto a principios del XIII. La victoria de Mutet, alcanzada por Simón de Monfort -donde muere Pedro II de Aragón-en el año 1213, fue decisiva, frente a los señores y condes del sur francés 5 . Honorio III, por bula de 19 de enero de 1217, incitaba a los maestros de París para que enseñasen religión en Toulouse, tierra desierta y llena de espinas y ortigas, cubil de dragones, tinieblas y sombras, concupiscencias y olvido de la justicia - decía, entre otras lindezas-. De esta forma volverían al Señor... Son años de pugnas y dificultades en París, por lo que algunos maestros y escolares enseñarian - todavía sin una organización o un estudio- en esta ciudad ${ }^{6}$. Surgiría hacia 1229, mediante el tratado entre Luis IX y Raimundo VII, conde de Toulouse, en el que una cláusula determinaba que, por diez años, el conde debería pagar salario a cuatro maestros en teologia, dos decretistas, seis de artes liberales y dos gramáticos; las clases dieron comienzo, bajo el dominio de los dominicos, que tan fuerte papel jugaban en la extirpación de la herejía ${ }^{7}$. Había aprobado los estudios el legado pontificio y, en 1233, el pontífice Gregorio IX confirma-

4 La exclusión de teología es evidente en el privilegio de Jaime II, citado en mi nota 14: wolentes tam in iure canonico quam civili, medicina, philosophia et artibus ac quibuslibet facultatibus aliis...». Véase J. VILLANUEVA, Viage, págs. 42-44, también el artículo de Sanahuja citado en la nota anterior.

5 R. STRAYER, The Abigensian Crusader, Michigan, 1992; acerca de Bouvines, G. DUBY, Le dimanche de Bowvines, 27 juillet 1214, Paris, 1973. Algunos datos sobre el personaje en J. R. MADDICOT, Simon de Monfort, Cambridge University Press, 1994, págs. 1-6, como padre de su homónimo, al que se dedica este libro.

6 H. RASHDALL, The Universities of Europe in the Middle Ages, edición de F. M. POWCKE y A. B. EMDEN, 3 vols, Oxford, 1936, reimpresión de 1987, II, págs. 160-173, en donde se recoge la bibliografia antigua. Existen algunos estudios, en torno a la fundación, entre los que cabe destacar las aportaciones en Les universités du Languedoc au XIIT siècle, Cabiers de Fanjeaux, 5 , en especial los de E. DELARUEJLLE y M.-H. VICAIRE, así como los de Y. DOSSAT, J. FAURY sobre colegios, o los documentos de H. GiLLEs. He de agradecer a mi amigo André Gallego la ayuda que me ha prestado en la bibliografia sobre esta universidad. La bula de Honorio III, en M. FOURNIER, Les statuts at privileges des universités francatses depuis leur fondation jusqu'en 1789, 4 vols. Paris, 1890, teimpresión 1970, I, núm. 502, págs, 437-438.

7 Fournier, I, núm. 505, pág. 440, cláusula del tratado de 12 de abril de 1229; el núm. 504 es una carta de los maestros y escolares dirigida a las otras universidades, en que, además de in- 
ba aquella universidad y le concedía diversos privilegios parisinos: tasación de las casas de los estudiantes por dos clérigos y dos laicos, jurisdicción de la curia eclesiástica — que no sean juzgados por jueces laicos-, incluso sobre quienes no fuesen clérigos, según la costumbre de la iglesia galicana; protección del conde y su baile y de los barones de la tierra sobre las personas y las cosas escolares, derecho de enseñar en cualquier lugar a sus maestros aprobados y graduados, y, por último, salarios pagados por el conde, según se había comprometido... Sin embargo, sucederían años difíciles, con luchas sangrientas entre dominicos y sus partidarios contra el otro bando - calificado de hereje-, encabezado por el conde tolosano, que dejarían sin vida el estudio y universidad 8 .

En 1245 el papa Inocencio IV, originario de Toulouse, promulga un conjunto de bulas que restauran situaciones y permiten el funcionamiento de aquella institución universitaria. Confirma y reproduce la bula de fundación, y extiende otros privilegios de París: juramento del canciller ante el obispo, de que concedetá grados de teología y decretos, según buena fe y conciencia, para honra de la facultad, sin admitit a los indignos; antes de admitirlos, tres meses después de solicitada la licencia, les examinaría de su vida, ciencia y conocimiento, junto a los maestros de teología y otros hombres buenos e ilustrados. Los maestros, antes de iniciar su lectura, juratían públicamente que enseñarán rectamente. El cancelario jura también que nada malo diría a los canónigos de los consejos de los maestros, que examinaría con justicia a los físicos, artistas y otros... Por lo demás, concedía a los maestros y escolares el poder de establecer constituciones $u$ ordenaciones - "porque donde no hay orden se encuentra el error con facilidad»- Fijaba el modo y hora de leer y disputat, se ocupaba de los vestidos, exequias fúnebres, de los bachilleres, quiénes, a qué hora, donde y qué materia se debe leer, tasas de los hospitales, así como el castigo para quienes contradigan estas constituciones; y si la falta fuera grave, como muerte o mutilación de miembro, o si fueran encarcelados pueden suspender las clases hasta lograr satisfacción. El obispo castigaría a los delincuentes y, si era necesario encarcelarlos, podrían librarse por una caución o, si se juzga indispensable por el obispo, se cumplirá en la cárcel del canciller. No podrán prenderse escolares por contrato o delito, si no es por el obispo; no se les exigirá pago para evitar excomunión o censura, ni el cancelario por la licencia. Las vacaciones de verano durarían un mes, pero los bachilleres podrían continuar sus lecciones. Los estudiantes no portarán armas ni turbarán la paz... Si mueren intestados, el obispo y los maestros se harían cargo de sus bienes, para retornatlos a sus he-

sistir contra la herejía, afirma la estabilidad de la nueva institución por la aprobación pontificia, la venida de muchos escolares de Paris y las delicias de la ciudad; la protección del conde y la posibilidad de conocer libros que están prohibidos en Paŕs. Véase Y. DOSSAT, «L'université de Toulouse, Raymond VII, les capitouls et le rois, Les universités..., págs. 58-91.

8 Bula de 30 de abril de 1233, confirmada y reproducida por Inocencio IV en 11 de septiembre de 1245 y Urbano IV en 1264, Fournier, I, núms. 506, 518 y 524, págs. 441, 449 y 524. Acerca de los conflictos hay extensa documentación en los núms. 508-517, págs. 442-447.

Hippania, LVIII/2, núm. 199 (1998) 515-536 
rederos o, si no comparecen, para destinarlos al ánima del difunto... ${ }^{9}$. Estos son los más viejos privilegios - de origen parisiense - de la universidad. Antes del inicio del siguiente siglo, apenas hay algún otro documento complementario, de forma que no podemos conocer con precisión la organización del estudio: es evidente la jurisdicción del obispo sobre escolares y maestros y los poderes del cancelario para intervenir y conferir los grados. Con todo, esta presentación me basta para emitir una hipótesis sobre la indicación de Bonifacio VIII hacia Toulouse.

En 1297 Toulouse era una universidad de creación pontificia. Bolonia, París o las inglesas habían nacido como reunión de profesores y escolares, que habían generado una enseñanza en un lugar, organizándose con mayor o menor predominio de los profesores o de los estudiantes. Concertados con los maestros pagaban por colecta, o se beneficiaban de los emolumentos que estos recibían de la comuna boloñesa o de los beneficios que gozaban los clérigos profesores de París. No existía en estos centros una concesión y planificación papal, sino que, más bien, los pontífices habían intervenido sobre un cuerpo ya existente ${ }^{10}$. Montpellier, basado en una escuela de medicina, presentaba una situación análoga ${ }^{11}$. Mientras, Nápoles era creación gibelina, del emperador Staufen, que quería desviar a sus súbditos de Bolonia, más sujeta al pontífice. No había intervenido la santa sede en su creación y funcionamiento: aunque el rey aragonés conocía la creación imperial, no imitó su organización ${ }^{12}$.

En segundo lugar, se sostenían sus cátedras por la cooperación y pagos del conde, sin que la iglesia tuviera que hacer frente, como en el caso de Salamanca o de Coimbra. Salamanca pareció que iba a ser financiada por el monarca Alfonso $\mathrm{X}$, pero pronto hubo de recurrir a las tercias concedidas por el papa, en tiempos de Fernando IV; después fueron confirmadas, por Clemente V y por

9 Las bulas de Inocencio IV, Foumier, I, núms. 518 a 523, págs. 449-452, la última, más extensa, recoge otra de Gregorio IX a París, DENIFLE, Chartularium, I, 149.

10 No puedo extenderme en la bibliografia boloñesa o parisina, me limitaré - aparte Rashdall, I- a S. STELLING-MICHAUD, L'université de Bologne et la pénétration des droits romain at canonique en Suisse au XIII et XIV sièctes, Ginebra, 1955; J. FRIED, Die Entstebung des Juristenstanden im 12. Jabrbundert. Zur sozialen und politischen Bedeutung in Bologna und Modena, Colonia-Viena, 1974; M. BELLOMO, Saggio sull'università nell'età del diritto commune, 1979; W. STEFFEN, Die studentiscbe Autonomie in mittelalterilichen Bologna, Frankfurt, 1981.

11 Los estatutos de medicina de 1220 fueron aprobados por el legado pontificio, mientras la bula de Nicolás IV de 1289 erigía en universidad las escuelas de derecho; en 1309 Clemente $\mathrm{V}$, señalaba libros para los licenciados, Fournier, II, núms. 882, 903 y 910; también en el Cartulaire de luniversité de Montpellier, 2 vols y suplem., Montpellier, 1890-1912, I, núms. 180, 210 y 220.

12 H. RASHDALL, The Universities.., II, págs. 21-26; F. TORRACA y otros,-Storia della Università di Napoli, Nápoles, 1924. Ya Denifle hizo notat la influencia literal del texto fundacional de Nápoles, sobre el privilegio de Jaime II de 1300, véase Die Entstebung der Universitäten im Mittelafter bis 1400, Berlin, 1885, pags. 499-508. 
Benedicto XIII. Coimbra, por su lado, aparece, desde su fundación, sostenida por aportaciones de las instituciones eclesiásticas ${ }^{13}$.

La financiación de Toulouse sería de cuenta del conde, el pontífice daba su aptobación y conservaba fuerte influencia eclesiástica a través del obispo y del canciller. Por tanto, el modelo tolosano satisfizo a Bonifacio VIII. Dejaba en manos de Jaime II la ubicación y costes, pero conservaba su poder, en unos reinos que habían estado cercanos a la herejía albigense. El rey aragonés, sin embargo, se sintiớ libre en relación a la organización del estudio de Lérida; no disponía de medios para financiarla, ni quiso someterla al obispo. El monarca diseñó un modelo para su nueva universidad, con inspiración boloñesa, y después encomendó a los paers de la ciudad — las autoridades municipales - que la regulasen y financiasen...

\section{LA UNIVERSIDAD SEGÚN EL MANDATO REGIO}

Las universidades medievales, con todas sus diferencias, poseen, entre sí, notables analogías. Yo diría que hay unos rasgos usuales, como son las asambleas estudiantiles o los claustros de maestros y doctores, una autoridad interna en el rector o rectores, un canciller en quien delega el pontífice la facultad de dar grados... Unas formas de enseñanza - la lectio y la disputatio- sobre unos libros en que se tesume el saber antiguo o medieval; unos grados, unos ritos... No hay, en consecuencia, posibilidad para innovar o inventat demasiado... Pero, en punto al poder — como también a su financiación — pueden estructuratse de diferente modo. Un viejo esquema, un tanto simplificador, distinguía entre Bolonia dominada por los estudiantes que nombran sus rectores y participan más en la elección de las cátedras, y París, en donde la hegemonía profesoral es indudable. Si se quiere, las inglesas constituirían una fórmula algo diversa por su configuración colegial -que alcanzaría a París en el otoño medieval-. La contraposición es cierta, pero la variedad es mayor si atendemos, con detalle, a los procesos de poder fuera y dentro de las universidades. Dicho con más exactitud: a los poderes del pontífice, del emperador -Nápoles fue fundada y regida por los soberanos- $-o$ de los reyes, la participación de la comuna o del municipio. $O$, desde dentro, los poderes de los estudiantes versus los doctores...

Jaime II ve ante sí unos cauces ya dados, pero puede modelar los resultados últimos - tampoco es menester imaginar unas opciones amplias, sino decidir, a la vista de precedentes una u otra solución-. No está sujeto a las prescripciones de la bula, que sólo le fuerza a mirar hacia Toulouse de un modo genérico, aunque el modelo general de las universidades limita, con sus precedentes, desviaciones.

13 Remito a mi estudio «Intertelaciones...», citado en nota 1 . Un resumen de la financiación, aunque tardio, P. CHACÓN, Historia de la universidad de Salamanca, edición de A. Carabias, Salamanca, 1990, págs. 65-73. La aportación inicial eclesiástica, en Coimbra, en A. Moreira de Sà, Chartularium, documento 2 -traducido en el 3-, de 12 de noviembre de 1288, págs. 6-9.

Hispania, LVIII/2, núm. 199 (1998) 515-536 
El primero de septiembre de 1300 , con acuerdo de la curia general o cortes de Zaragoza, determina la localización del estudio general en la ciudad de Lérida. Dirigiéndose a los paers y hombres buenos de aquella población, expone las razones y la autoridad por que hace la fundación. Pensaba que era útil formar hombres prudentes en doctrina y estudios que complacerían a Dios, a sí mismo y a sus tierras, produciendo frutos saludables. Su empeño fue que alcanzasen aquí alimento de su ciencia y no tuviesen que salir a tierras peregrinas para conocer las ciencias, ni se viesen obligados a mendigat en aquellas regiones... La facilidad del estudio y los altos costes eran, sin duda, razones de peso. Después da noticia de la bula papal y designa Lérida, tras diligente consideración y consulta de la curia, por ser «huerto de fertilidad, intermedio de nuestras tiertas y reinos" así como su nobleza, lealtad y fe, o los servicios prestados a los reyes... ${ }^{14}$. Importa su posición central en los reinos, pues ha de servir a todos sus súbditos de camino para el estudio de leyes, cánones, medicina, artes y otras facultades y ciencias. Le confiere el monopolio de estos estudios en sus dominios, bajo severas penas. Cuando los monatcas peninsulares establecieron en el siglo XIII estudios generales, pensaron que bastaba uno en cada reino: Alfonso VIII sostuvo Palencia en Castilla, mientras Salamanca fue leonesa - la unión de 1230 coadyuvó quizá a extinguir la primera-. Don Dionís fundaría la portuguesa de Lisboa, después trasladada a Coimbra... ${ }^{15}$.

Todos los poderes de organización de Lérida estaban en manos de Jaime II - el papa se había limitado a la concesión dé los privilegios, indulgencias, libertades e inmunidades de Toulouse-. Pensó el rey que se requería una regulación que conservase estas gracias y libertades, para incremento y perfección del estudio. El monarca invitaba a los paers, hombres buenos, y a todos los vecinos de Lérida, en su nombre y de sus sucesores, para que tengan, gobiernen y ordenen aquella universidad, a salvo los privilegios reales que pudieran concederse y los pactos y convenciones, o cualesquiera prescripciones y ordenaciones que se hiciesen para bien de la universidad por él o sus sucesores. Por tanto, hay desde los inicios una presencia municipal, concedida por el rey para mayor facilidad de instalación y funcionamiento. Sin duda, está inspirada en la actividad de la comuna boloñesa, pero ésta era órgano de poder de una ciudad libre; por esa diferencia, Jaime II conserva los poderes de la corona y sus facultades de intervención en su universidad... El tenía la soberanía y la jurisdicción.

De inmediato, va a ejercer sus poderes, mediante la promulgación de unos estatutos u ordenaciones, que sin duda acompañaban, como conjunto de me-

14 Se reproduce en J. VillanuEva, Viage, t. 16, núm. 3, págs. 196-198; España sagrada, t. 47, núm. 68, págs. 341-343; Bofirull, Documentos, 6, núm. 62, págs. 204-208; AjO, Historia, I, núm. 30, págs. 454-455. Edición y facsímil en 700 aniversari, págs. 22-23.

15 Acerca de una universidad para cada teino, véase M. PESET, «Modelos y estatutos de las universidades españolas y portuguesas (siglos XIII-XVIII)", Accademia peloritana dei pericolanti. Atti, (Messina) 60 (1991), págs. 65-105, en especial las primeras páginas. 
didas primeras —están fechados el día 2 de septiembre del $1300-{ }^{16}$. Se dirige a los maestros y escolares, presentes y futuros, insiste sobre sus buenos deseos y la localización en Lérida, según había decidido en curia plena, con la autoridad concedida por la santa sede y la suya propia. Lérida era el lugar común y casi intermedio de nuestras tierras y gozaba de fertilidad en vituallas, clima modezado, abundancia de aguas y ríos, nobleza de sus ciudadanos y decoro de sus pobladores... Había recibido las indulgencias, gracias e inmunidades de Toulouse, pero, en vista de su fomento e incremento, decidió dotarla de estos estatutos que miraban más bien hacia Bolonia. Dos cuestiones esenciales interesaban al monarca: la configuración de las autoridades de la universidad y la delimitación del fuero universitario.

\section{LAS AUTORIDADES ACADEMICAS: EL CANCILLER}

Lérida, en sus primeros estatutos imitaba más de cerca a Bolonia que a la universidad tolosana. ¿Prefieren el monarca y sus consejeros - que quizá han estudiado en Bolonia - copiar aquella gloriosa y primera universidad de juristas? El rector sería nombrado por los escolares, según veremos, y tendría la jurisdicción escolar - no se atribuiría al obispo como en Toulouse-. El canciller interviene en los grados, «que se confieren como se observa en los dichos estudios generales»; pero su designación correspondexía al monarca, en un canónigo de la catedral ilerdense...

El canciller, como representante de la iglesia, concede el libro y la facultad de enseñar, por sí o por medio del vicecanciller. Previamente, el candidato ha sido examinado, privada y públicamente, por el rector y los doctores y maestros... El canciller era vitalicio y actuaría por autoridad apostólica y real. Estaría presente en el examen, sin recibir ningún emolumento por su presencia o autoridad, ni por el sello o la escritura del grado - su notario se limitaría a cobrar unas tasas o cantidades determinadas por el rey-. Entre las primeras disposiciones, el 5 de septiembre, se designaba a Juan de Torrefeta, como canciller, para conferir los grados a doctores y maestros, en persona o por su vicecanciller, al que elegía... ${ }^{17}$.

16 J. VILLANUEVA, Viage, t. 16, núm. 5, págs. 200-207; V. DE L.A FUISN'L', Historia de las universidades, I, págs. 303-304; España sagrada, t. 47, núm. 69, págs. 343-348; BOFARUII, Documentos, 6, núm. 63, págs. 208-217; AJO, Historia, I, núm. 31, págs. 455-459. En 5 de septiembre de 1300 nuevas disposiciones prohibían los estudios fuera de Lérida en todos los territorios del monarca, Viage, t. 16, núm. 4, pág. 199; España sagrada, núm. 70 y 71, paigs. 348-349 y 349-350, este último en BOFARUl.J., Documentos, 6, docs., 64, 65 y 66, págs. 218-221; Ajo, Historia, I, núms. 33 y 34, págs. $460-461$.

17 Editada por E. SERRA RAFOls, Una universidad medieval. Elestudio general de Lérida. Discurso..., Universidad de La Laguna, Madrid, 1931, pags.67-71; AJO, Historia, I, núm. 35, pág. 461. Su figura y sus dudas en tomar posesión del cargo, R. GAYA MASSO', Cancilleres y rectores del estudio general de Linida, Lérida, 1951, págs. 5-6 y 21-23.

Hiquania, JVII1/2, núm. 199 (1998) 515-536 
Apenas guarda analogía con el canciller tolosano, nombrado por el obispo, o en su defecto por el cabildo catedralicio, que recaeria usualmente sobre un canónigo. Su poder es mayor en Toulouse, ya que participa en numerosos actos o recibe el juramento del rector electo. Y aunque no tiene jurisdicción o poder de juzgar - lo retiene el obispo- aparece siempre con preferencia sobre los rectores ${ }^{18}$. Tampoco el boloñés —el archidiácono de la catedral- gozaba de facultades de juzgar, a diferencia del poderoso maestrescuela o escolástico salmantino, nombrado por el pontífice, que era juez del estudio ${ }^{19}$. És quizá el canciller ilerdense una imitación de Bolonia, si bien, bajo la autoridad real...

El Liber constitutionum, et statutorum ilerdense dedicaba dos rúbricas al cancelario: en la primera aceptaba que su nombramiento pertenece al monarca, no pudiendo la universidad designarlo ni siquiera interino en las vacantes; la segunda, De officio cancellarii, reúne un sinfín de cuestiones, sobre todo, en torno a los grados, que son su función. «El oficio del cancelatio consiste en autorizar y aprobar a los doctores y maestros que son aceptados al honor magistral en este estudio. El cancelario, como es uno de los oficiales principales del estudio, goza de los privilegios de la universidad ${ }^{20}$. Sus facultades, en torno a los exámenes de grado están bien delimitadas, minoradas. Quien es aprobado en el examen privado por los doctores y maestros, si el cancelario lo considera insuficientemente preparado, por reserva o por algún temor, puede prohibirle la lección o examen público con consejo del rector, consiliarios y algunos peritos en la materia. Pero, si es aprobado, en el privado, por segunda vez por la mayor parte de los doctores y maestros, no puede denegat la licencia. $Y$ no es preciso realizar el ejercicio público de inmediato, se puede tardar años, sin que se anule el tentament o examen privado. La dilación puede ser necesaria, si el cancelario, con consejo de los doctores lo defiere a un término o plazo, para que logre mayor suficiencia, o por algún defecto temporal o impedimento. $\mathrm{O}$ voluntaria, si, aun pudiendo, el interesado aplaza el examen. También vigilaría que se cumpliesen los estudios previos al grado: siete años en leyes, cuatro en cánones - junto a treinta lecciones ordinarias o extraordinarias--, según se dice, conforme a un estatuto consultado de Bolonia, a la que, no sin causa, llamamos madre de las

18 FOURNIER, Les statuts et privileges..., I, núms. 523, 526, 527, 561, 563 y siguientes, en los que se va introduciendo la jurisdicción del senescal y de los capitulares, págs. 451-453, 512 y siguientes, con otra documentación sobre los conflictos de jurisdicción. Véase H. RASHDALL, The Universities ..., II, págs. 170-171.

19 Aparece ya en 1254, se confirma en 1333, véase V. BELITRÁN DE HERLDIA, Cartulario, documento 23, también 85 y 95 y Bulario, docs. 14, 26, 28, entre otros. Todavía en Partidas, 2, 31,7 no parece ejercerla, pues debían de ser demandados «delante de su maestro, en su escogencia es de responder a ella o delante del obispo del logar, o delante del juez del fuero, qual más quissiesses, más cerca de la Habita federiciana y el texto alfonsino fundacional.

20 Liber constitutionum et statutorum generalis studii ilerdensis, editado por J. VHL.ANUEVA, Viage, t. 16, núm. 6, págs. 207-234, fechado en 28 de septiembre de 1300 . Sobre las actuaciones previas del municipio, R.GAYA MASSOT, "Comentarios al periodo preparatorio de la fundación del estudio general de Lérida», Ilerda, 12 (1949), págs. $57-72$ o en Cancilleres y rectores, págs.1-6. 
leyes, legum nutricem... ${ }^{21}$. Nadie puede dispensar de estos cursos y requisitos, ni el rector ni el canciller ni otra persona, pues sin estos años es dificil, en especial al estudiante foráneo, la suficiencia para la prueba...

Veamos ahora la jurisdicción académica que recae en la universidad de los escolares, en su cabeza, el rector del estudio.

\section{JURISDICCIÓN Y FUERO}

Las ideas sobre el poder y su articulación, en los comienzos de la baja edad media, están basadas, en buena parte, en los textos romanos. La potestas se recogia en los conceptos de imperium y de iurisdictio, que correspondian en su forma más alta al príncipe, identificado con el emperador o con los diversos monarcas - mientras, el papa recibía su poder temporal de la falsa donación de Constantino y los espirituales de su posición al frente de la iglesia, junto a los concilios-. La jurisdicción se definía por Azo como upotestad introducida por el pueblo para dictar derecho coactivamente y estatuir la equidad, 22. Su ambigüedad reunía en sí dos vías que hoy concebimos diferentes: legislar y juzgar.

La potestad de dar normas o leyes generales correspondía al príncipe, cuanto le placiera tenía fuerza de ley. Si bien, otros magistrados poséan esa facultad en ámbitos más restringidos. En todo caso, las universitates o colectivos de petsonas - como las ciudades - podían aprobar estatutos para regirse. La fuente de la norma era el pueblo romano, que había trasladado su poder al príncipe, pero algún texto reconocía esa posibilidad de establecer normas de menor rango por una ciudad ${ }^{23}$. La realidad medieval evidencia que las universitates o colectivos de personas daban estatutos, juzgaban sus propios conflictos, tanto las ciudades como los comerciantes o quienes tenían una misma profesión ${ }^{24}$.

La facultad de juzgar la poseía asimismo el príncipe, quien la delegaba a diferentes magistrados, que la ejercían de forma ordinaria. Pero también en este aspecto, las universitates, según Azo, podían nombrar sus iudices o rectores por

21 Liber constitutionum, rúbrica De officio cancellanii, págs. 219-223, en la 220: «Non sine causa Banoniae, quam legum nutricem recte vocamus, statutum esse comperimus...n.

22 Summa Azonis, sine locuples iuris civilis thesaurus, Venecia, Apud Societatem minimam, 1610 , in C.3,13, columnas 176-177, núm. 1. Sobre esta definición, y en general sobre estos conceptos, J. VALLEJO, Ruda equidad, Ley consumada. Concepción de la potestad (1250-1350), Madrid, 1992.

23 Véase Digesto $1,4,1 ; 1,1,9$ y Código $1,14,12,3$.

24 Summa Azonis, cols. 176-177: «Item dat iurisdictionem ordinaria universorum consensus, licet confirmatione indigeat prefecti pretorii, ut in Authentica de defensione civitatis, interim, et illud et si eadem. Item qui exerceat aliquam negotiationem, vel professionem. Item consensus eorum qui sunt de eadem professione, vel negotiatione, ut infra eol. ult. Privatorum autem singulorum duorum, vel trium, etiam plurium (ex quibus non constinitur universitas vel civitas, vel castri, vel villae, vel burgi, vel congregatio professionis, vel negotiationis) consensus non instituitur, nec facit iudicem...\%. También la doctrina canónica insistró en el poder de las universitates, por ejemplo, Inocencio $\mathrm{N}$ en su comentario a Decretales.

Hi.pania, J.VIII/2, núm. 199 (1998) 515-536 
elección de sus miembros, como en ciudades, villas o campamentos, o los comerciantes o miembros de una profesión. No alude a la posibilidad de darse estatutos o juzgar de los estudios generales o universitates scholarium; con su apego a los textos romanos describe las enseñanzas de derecho que se daban en Beyrut y Constantinopla, su monopolio ya desaparecido, pues ahora son muchas, en especial Bolonia maxime y también en Módena, donde él explicaba los arcanos del derecho ${ }^{25}$.

Por otro lado, en el juzgar según la amplitud de la jurisdicción se distinguía entre mero y mixto imperio. El primero correspondía al príncipe, aunque podían tenerlo algunos altos magistrados y también delegarlo: juzgaban todas las causas civiles y criminales, incluidos los delitos que suponen penas de muerte o espada, y otros. En la práctica fueron aquéllos que llevaban aparejada la pena capital o la mutilación de miembro. El mixto imperio, menor, no podía conocer de estos delitos ${ }^{26}$.

En los siglos XII y XIII los condes catalanes y los monarcas de Aragón habían hecho concesiones a la ciudad de Lérida, desde estas premisas: si bien el poder procedía del tey, lo delegaba o reconocía la autonomía de la ciudad o colectivo de personas. A través de las Consuetudines ilerdenses de 1228 se percibe cómo depende la jurisdicción de la ciudad de concesiones regias. En Italia -la patria de Azo y de la glosa - la articulación del emperador y las ciudades demandaba una mayor autonomía de las universitates. En Lérida, Guillermo Botet, al redactar las Conswetudines, empieza declarando su dependencia y prelación: "Constituye nuestro derecho las donaciones y concesiones o privilegios de los príncipes, en las costumbres escritas y no escritas, en los Usatges, en las leyes góticas y las romanas) ${ }^{27}$. En este texto aparecen recogidas las tres primeras, ya que Usatges o las leyes de los godos o romanas quedan, naturalmente, aparte; en último término, las romanas, refieren al ius comune. Empiezan las Consuetudines por las donaciones de los condes y de los monarcas posteriores. Aparece en estos textos no sólo el batlle real, sino el juez o curia y, en una donación de Pedro II, la concesión del consulado para todos los siglos, a salvo la fidelidad a su persona y al conde de Urgell y el derecho de los tenentes de castillos: se elegirían

25 Summa Azonis, texto de la nota anterior; sobre estudios general, columnas $980-981$.

26 Summa Azonis, columnas 178-179; señala un tercer apartado de modica coertione, pero to refunde en el mixto. Pertenecen al mero imperio las confiscaciones de bienes, las privaciones de libertad o del status civitatis, según Azo.

27 Las Consuetudines fueron publicadas por vez primera por J. VILLANULVA, Viage, t. 16, págs. $160-196 \mathrm{y}$, en forma definitiva por P. LOSCERTALLS DE VALLDEAVELLANO, Costumbres de Lérida, Barcelona, 1946, edición que se cita. Acerca de su derecho, J. M. ${ }^{2}$ FONT RIUS, La reconquista de Lériday su proyección en el orden juridico, Lérida, 1949, así como sus Cartas de población y franquicia de Cataluña, 3 vols, Barcelona, 1969-1983; F. VALLS TABERNER, «Las 'Consuetudines ilerdenses' y su autor GUILLERMO BOTET), Revista juridica de Cataluña, 19 (1913) 155-210, «Les fonts documentals de les 'Consuetudines ilerdenses'y, Estudis universitaris catalans, 11 (1926), págs. 137-171, también en Obra selecta, II, núm. 14, págs. 126-134, Madrid, 1954, y «Les 'Consuetudines ilerdenses' de GUILJEM BOTETy, Estudis d'histöria juridica catalana, Barcelona, 1929, págs. 84-87, en Obra selecta, II, núm. 13, págs. 123-125.

Hitpania, LVIII/2, núm. 199 (1998) 515-536 
cada año cuatro cónsules, con otros consejeros, que podrían dar ordenaciones y gobernar al pueblo de Lérida, defender a las personas y a las cosas... ${ }^{28}$. A continuación, el libro segundo recoge las costumbres escritas, «cotos, bandos y estatutos», que los cónsules con su consejo pueden dar y vigilar a través de dos encargados, y recoge numerosos estatutos municipales acordados o escritos... $Y$ por fin, en el libro tercero, en las costumbres no escritas, que ahora se fijan y redactan, aborda las cuestiones más interesantes sobre la jurisdicción, en general sobre procedimiento...

La ciudad de Lérida se halla constituida como una universitas de sus ciudadanos, a la que los condes y monarcas han concedido autogobierno. Los cónsules - convertidos en paciarii en $1264^{29}$ - pueden dar normas, como las que se recogen en el libro segundo, o recopilar las costumbres por que se rigen... La alta justicia corresponde a los cónsules o a los paers. «En aquellos crímenes que llevan consigo pena corporal, no juzga el curia, sino los cónsules y prohombres, cuyas sentencia ejecuta el curiay. Mientras, la baja jurisdicción se atribuye al curia, en un principio designado por los paers y sus prohombres, luego absorbido por el poder regio. A partir de 1300 se simplifica y se atribuye al curia toda la jurisdicción "se le otorga la alta» ${ }^{30}$. Ante el curia tesponde cualquier persona que se halle en Lérida, aunque sea de otro lugar o fueto, salvo clérigos o religiosos... Los hospitalarios incluso, están sometidos al curia. Los nobles o caballeros también, en caso de contrato o de daños contra ciudadanos o sus cosas. Los nobles o caballeros vecinos que tengan aquí sus posesiones responden como los otros ciudadanos. El sarraceno acudiría a su zalmedina, pero si actúa o es citado ante el curia, debe responder, como todos los demás privilegiados ya mencionados... Las sentencias no eran escritas, ya que bastaba pronunciarlas, a no ser que la parte lo exigiera. Tampoco es preciso que la apelación sea escrita; la resuelve el curia con otros sabedores de

28 Costumbres de Lérida, 32, pág. 28. Véase mi nota siguiente.

29 J. LALINDE ABADIAA, "El 'curia' o 'cort'. Una magistratura medieval mediterránea", Anuario de estudios medievales, 4 (1967), págs. 169-299, en pág. 210, Jaime I, en 27 de diciembre de 1264. Sobre el municipio, R. GRAS, La pahería de Lérida. Notas sobre la antigua organización de la ciudad, 1149-1707, Lérida, 1911.

30 Castumbres de Lérida, núm. 163, el citado, pág. 72. Esta alta jurisdicción de los cónsules, de los paers, parece modificarse con los años; el rey recaba como propia esta magistratura y la une al veguer, aunque sea de nombramiento municipal, la puede prorrogar; en 13 de junio de 1300 Jaime II parece conceder las causas criminales con muerte o mutilación al curia, ayudado por dos paers y diez prohombres, véase J. LALINDE ABADí $A$, «El 'curia' o 'cort'... » en especial 210-225, así como los documentos 2 y 4 . Esta nueva solución parece estar presente en las ordenanzas de 2 de septiembre de 1300 - citadas en nota 16 - al perdonar las deudas anteriores a la venida al estudio. udemque super criminibus vel delictis quae mortis penam non ingerunt, per eos ante quam ad studium venire comissis, volumus observari, nisi jam fuissent per vicarium vel curiam et paciarios Illetde banniti et preconizati ratione malefactorum ipsorum. Itemquae quod nullus praedictorum capiatur, vel captus detineatur in personá pro ullo levi crimine seu delicto, quod penam mortis seu membri abcisionem non ingerat delinquenti, dum tamen fideiussores vel caplevatores coram suo judice possint oferre ydoneos...»

Hitpania, LVIII/2, núm 199 (1998) 515-536 
derecho ${ }^{31}$. Por tanto, la corporación municipal poseía tanto la facultad de darse normas, como la de juzgar las causas que se originasen en su ámbito, con autonomía más o menos amplia para otros grupos: eclesiásticos, nobles y sarracenos... La universidad o estudio debe lograx un espacio propio, cierta jurisdicción, para velar por su existencia y sus privilegios, si no quieren verse sometidos al dominio municipal, con la desventaja de ser extranjeros o no ciudadanos. La solución tolosana atendía a este problema sometiendo la universidad a la jurisdicción eclesiástica. Pero Lérida prefirió seguir la tradición boloñesa.

\section{DEL RECTOR Y SU JURISDICCIÓN}

Jaime II, en sus ordenaciones de 2 de septiembre de 1300, permitía la existencia de una universitas de escolares, a la que confería potestad de autogobierno. Le autorizaba a elegir su cabeza, un rector anual, que presidiría la universidad y el estudio. Junto a los consiliarios -representantes de las naciones- podría aprobar estatutos u ordenaciones y ejercería facultad de juzgar sobre las cuestiones o conflictos que se planteasen...

El rector sería elegido cada año, por los estudiantes foráneos de leyes y cánones, clérigos y laicos, que no fuesen ciudadanos de Lérida. La universidad, por tanto, estaría constituida tan sólo por los escolares juristas foráneos: es decir, como en Bolonia la universidad ultramontana, con su rector, consiliarios y naciones, pero sin esa dualidad de la otra cismontana, que reunía a los originarios de la península itálica. Aquí se excluía a quienes eran vecinos de Lérida, que, sin duda serían más numerosos y estaban más protegidos por el derecho de la ciudad. Los estudiantes de otras materias o facultades - médicos y artistas excluidos de la elección, de la universitae - quedaban englobados en el estudio general, bajo el gobierno del rector, asi como también los doctores y maestros, a diferencia de Bolonia. El rector y los consiliarios serían estudiantes de uno de ambos derechos y tendrían, sobre los doctores, maestros y escolares de cualquier ciencia, residentes en el estudio, la potestad que suelen en el estudio boloñés u otros estudios generales, según ordenaba el monarca, aun cuando su regulación era algo distinta ${ }^{32}$.

Sobre las pautas marcadas por el rey, el Liber ilerdense precisa la elección del rector y sus poderes. En la víspera de la purificación de la Virgen, el 1 de febrero de cada año, el rector debía reunir la universidad de estudiantes juristas en la iglesia del Beato Martín; tras una misa solemne, cada una de las doce naciones

31 Costumbres de Lérida, núms. 106, 145 y 154. No obstante, en el añadido de Jaime I en 1265, págs. 75-76, De statutorum regis Jacobi super iudicia, se percibe ya una justicia escrita ante el curia, con abogados.

32 Las ordenaciones de Jaime I de 2 de septiembre de 1300, véase mi nota 16: «quam in studio Bononiensi, et in aliis studis generalibus...» Acerca de la jurisdicción en Bolonia trataré más adelante, véase la nota 42 . 
designa su elector, por unanimidad o la mayor parte - en caso de empate decide el consiliario respectivo-. Juran los electores que actuarán según conciencia - sin ceder a odio, gracia, precio, temor o amor, en el nombramiento del nuevo rector-. Votan en secreto ante el rector saliente, su notario o escritor y tres consiliatios. Si del escrutinio, publicado ante los doce electores, alcanza algún escolar dos tercios, es proclamado rector-debe pertenecer a la nación a que corresponde ese año el rectorado-; en otro caso, si no los alcanza, se continúa la votación o se somete a tres o más árbitros, designados por y de entre los electores. No cabe interrumpir la elección, salvo por una súbita e inevitable necesidad; el rector puede solicitar ayuda al curia para conseguir que se continúe... El rector debe salir sucesivamente de cada una de las doce naciones. Los redactores del Liber constitutionum fueron muy optimistas acerca del futuro de su universidad, ya que pensaron que atraería escolares de todo el orbe, a imitación de Bolonia - aunque constituyeron sus naciones con distintas delimitaciones, al estar centrada en otro punto, y sin separar las dos universidades cismontana y ultramontana boloñesas-. La realidad limitó a alternar rectores catalanes y aragoneses, hasta el siglo XV, en que Alfonso de Borja, futuro papa Calixto III, consiguió el turno para los valencianos. Los consiliarios se elegían por naciones - con casi idéntica distribución- sin que se especifiquen los mecanismos de elección ${ }^{33}$.

El rector y sus consiliarios gozaron de amplias facultades en el gobierno del estudio general. Presiden la universidad, concebida como asamblea o corporación de los escolares de ambos derechos, no vecinos de Lérida. Sin embargo, algunos poderes limitaban el autogobierno de los escolares: el monarca, en primer término - - el papa con menor frecuencia-; también el municipio, los paers

33 Liber constitutionum, citado en nota 20, De electione rectoris, págs. 211-214. Las naciones eran: primera, las diócesis de Barcelona, Tarragona, Mallorca, Tortosa y Lérida; segunda, las de Zaragoza y Segorbe; tercera, Urgell, Vic y Gerona; cuarta, Huesca y Tarazona; quinta la diócesis de Valencia y la de Cartagena; sexta la hispana, formada por las de los restantes reinos peninsulares; séptima —empiezan las ultramontanas-, la Narbonense; octava, los vascos y todas las que están más allá hasta el océano y los limites de la Galia, con Provenza y hasta los borgoñones y genoveses; novena, genoveses e italianos hasta el mar Adriático; décima, los gálicos o borgoñones y las gentes de más allá hasta los teutones; undécima, las naciones teutónicas hasta los límites de Europa y duodécima, ingleses, escoceses e islas del océano. En verdad, se limitaria a aragoneses y catalanes, hasta inicios del XV en que entran los valencianos en el turno, véase, los que se conocen, en R. GAYA MASSOT, Cancilleresy rectores..,; también su trabajo «Los valencianos en el estudio general de Léridas, Anales del centro de cultura valenciana, anejo 3, Valencia, 1950. Sobre los consiliatios, las rúbricas De electione consiliariorum y De temporibus ordinandorum, sive eligendorum officialium studii, págs. 214-215 y 217, en donde se indica su elección tres días después del rector. Las naciones corresponden a las diócesis de Lérida, excluida la ciudad; Urgel y Vic; Tarragona y Mallorca; y Tortosa; Huesca y Tarazona; Zaragoza y Segorbe; Valencia y Cartagena; Natbona; las tierras de España; de todas las demás ultrapirenaicas, si hay escolares, otro consiliario cada una. Resulta extraña, la omisión de Barcelona, Tortosa o Gerona. Sin duda, se debe a un error; dado que se quiere repetir lo establecido pata la elección de rector usi bien con una más, la ilerdensen, es fácil suponer que se agrupaban como alii. El texto, además, repite indebidamente la de Lérida.

Hispania, LVIII/2, nüm. 199 (1998) 515-536 
y hombres buenos, que financiaban y se arrogaban poderes, como asimismo la catedral. En los inicios, las pugnas entre los escolares, los poderes municipales y el obispo con su cabildo catedralicio dificultaron el desenvolvimiento de los estudios; se llegó a cerrar la universidad. Después, alcanzaron un acuerdo o concordia y pudo funcionar con normalidad, con un cuerpo o claustro, compuesto por seis clavarios - dos municipales, dos catedralicios y dos procedentes de la universidad-que tendería a resolver las cuestiones de profesorado y finanzas, como una instancia superior a la universidad o asamblea de escolares ${ }^{34}$.

Jaime II les había otorgado al rector y consiliarios la aprobación de estatutos y la facultad de imponer penas y multas. En el Liber se perfila mejor su poder, atribuyéndolo a la universidad: se reproducía la bula y las dos cartas del rey de 1 y 2 de septiembre, que autorizaban a los paers a ocuparse del estudio. Da cuenta el Liber de la elección del primer rector, Pedto de Cabrera, archidiácono de la catedral, y de cómo éste, con sus consiliarios y toda la universidad de juristas, aprobaban este texto, realizado por Pedro de Valls, cura de Tamarit, y el jurista municipal Bernardo Bonet, principal autor. Establecía el Liber: «El estatuto perpetuo o constitución general promulgados por el rector de este estudio o por cualquier persona inferior, no tienen valor, si no están confirmados mediante la aprobación de toda la universidad de escolates, que estudian aquí uno u otro derecho, o de su mayor parte». Principio que varía la propuesta del tey, que atribuía esta facultad al rector y consiliarios; ahora se establece el auténtico poder, la universidad. Quizá por ello, para disimular la autoafirmación de poder, se apostillaba: "Contra los privilegios concedidos por el señor rey o los ciudadanos de Lérida, no se puede ordenar ningún estatuto». Incluso quieren liberarse de la sujeción a las bulas concedidas a Toulouse, de sus estatutos o constituciones, que sólo valdrían si fuesen admitidos por el rey o por la universidad. Aun admitidos, puede renunciarse a ellos, cuando se juzgue oportuno... ${ }^{35}$.

El rector y sus consiliarios aconsejan en la selección de profesores, pero se nombran por el municipio. Pero eligen el bedel y el estacionario, a no ser que se prefiera que se haga por toda la universidad ${ }^{36}$. Los profesores, sin el permiso del rector y consiliarios, así como del municipio, no pueden ausentarse de la ciudad —si se le permite podrá poner sustituto-; ni tampoco cambiarían la

34 Acerca de la claveria, aparecen en 1313 citados por vez primera en el nombramiento de un profesor, R. GAYA MASSOT, (El Chartularium...), I, núm. 2, pág. 42. No voy a entrar en el desarrollo del estudio general durante los años posteriores, véase R. GAYA MASSOT, Cancilleres y rectores...; E. SERRA RAFOLS, Una tniversidad medieval... En el Liber está atribuido directamente a los paers el nombramiento de profesores y de "bancarios», VILLANUEVA, Viage, págs. 214, 215 y 217. Véase R. GAYA MASso'r, «Provisiones de cátedras en el estudio de Lérida», Analecta sacra tantra conemsia, 30 (1957), págs. 233-296.

35 Estas citas y materia pertenecen a las primeras rúbricas del Liber constitutionum, Rubrica de constitutionibus et statutis, De rescriptis, De consuetudine y De postulatione, págs. 208-211.

36 La elección del bedel y estacionario, una vez muetto el nombrado por el rey, Liber constitutionum, De electione bedellorum et stationani studii, pág. 215. Los bedeles particulates de las escuelas se ponen y deponen libremente por los doctores. De su oficio, págs. 223-226. 
lectura o texto, o el lugar en que enseña a otra parte de la ciudad. Los doctores y maestros asalariados por la ciudad, sólo pueden poner sustituto dos veces a la semana, con causa justa y permiso del rector ${ }^{37}$. En cambio, no aparece la asignación de puntos - menos todavía se determinan las materias en constituciones, como es usual en el XVI-, sin duda porque sería el municipio quien lo haría al proveer las cátedras... Queda, por tanto, suficientemente claro el poder del rector y de la universidad para establecer estatutos, que son obligatorios para todos los componentes del estudio. La sujeción a los estatutos y a los poderes del rector se afianza con el juramento que deben prestar todos los doctores y maestros, sean ciudadanos o foráneos, los bachilleres y escolares, de obedecer al rector in licitis et bonestis; incluso el bedel y el estacionario. Si alguno no lo hiciese, tras ser advertido por tres veces, sería expulsado del estudio. Tan sólo están dispensados de jurar los estudiantes de Lérida, aunque estén obligados a respetar los estatutos, mientras estuviesen en el estudio; y si quieren explicar alguna materia, deberán jurar la obediencia al rector. No es fácil explicar esta excepción de los ciudadanos, tal vez les supondría una doble fidelidad, si juraran su pertenencia a la corporación municipal y a la universidad... Para mayor respeto de los estatutos universitarios, se prohibía pedir un rescripto del príncipe que los dispensase, cuando fuese citado por el rector y consiliarios, con el fin de no acudir, o cuando fuese suspendido o expulsado del estudio para solicitar la anulación; ni tampoco acudir a otras instancias o jueces distintos de los señalados por el monarca... ${ }^{38}$.

$\mathrm{El}$ rey, por otro lado, protegió la vida e independencia de su universidad a través de una serie de privilegios, que aseguraban la paz o coto real. Los doctores, maestros, escolares y sus socios y familiares, domésticos, estacionario, bedel, librero o escritor que moraren en el estudio no podrán ser cogidos, detenidos o prendados en su persona y bienes por deuda anterior a su llegada, salvo que sean deudores principales o fiadores, pero se podrían liberar dando fianza de detecho ante el juez competente. Como tampoco por delitos o crímenes que no supongan pena de muerte, cometidos antes de venir al estudio $o$, después, siempre que sean leves y ofrezcan fiador adecuado al juez... No se realizarán pesquisas o indagaciones en las casas de los estudiantes por los oficiales reales, salvo que se trate de crímenes que llevan aparejada muerte o mutilación, y en este caso se haría ante autoridades escolares y sin causar daños... Para seguridad de los estudiantes no se permitirá que en el recinto universitario entren ciudadanos o extraños y provoquen riñas tumultuarias, ya que serían castigados con elevadas multas y azotes. Y si levantan al pueblo e invaden las casas de los estudiantes, se les cortaría la mano o se les ahorcaria, según la gravedad del caso. Se quiere conceder protección y guidático o tregua, de forma que si alguno en riña o fuera, golpease atrozmente, hiriese o matase a algún doctor maestro o estudiante, su persona y bienes quedarían a voluntad real, a no ser que le hubiera desafiado ante tres testigos con

37 Véase la rúbrica De traslatione, pág. 216.

38 Rúbrica de jurejurando, pág. 229 y De rescriptis, págs. 209-210.

Hixaniu, LVIII/2, núm. 199 (1998) 515-536 
cinco días de antelación; en cuyo caso el doctor o escolar puede pedirle seguridad a los oficiales reales. Así como se les eximía de algunos impuestos, de lezda y peaje, u otros derechos, por las cosas que traian, como vituallas o caballerías, libros y pergaminos... Aseguraba el monarca que podrían venir maestros y escolares y demás componentes o auxiliares del estudio, con su familia y sus cosas, libre y seguramente bajo fe del rey; salvo que fuesen personas sospechosas, pero aun en este caso les permitiría volverse con tiempo suficiente a las tierras enemigas o con las que estuvieran en guerra ${ }^{39}$. En suma, se concede una paz a la universidad y al estudio - a todos sus componentes-. Se pretende la creación de una corporación de estudiantes autónoma y dotada de amplios privilegios, para favorecer al estudio. La universidad de estudiantes juristas foráneos elige sus autoridades y aprueba sus estatutos o constituciones...

\section{EL, TRIBUNAI, DEL RECTOR}

La jurisdicción, en sentido amplio — tal como vimos en Azo- lleva consigo una potestad de dar normas y otra de juzgar los litigios - a esta última se la denomina, en la terminología más moderna jurisdicción-. He examinado ya la primera, en tanto el rector, sus consiliarios y la universidad, o al menos su mayor parte, pueden aprobar constituciones generales o estatutos perpetuos... Incluso, de pasada, he podido observar los poderes disciplinarios que se atribuyen al rector, con o sin sus consiliarios, en la vigilancia del orden académico o la participación que tiene en la elección de los profesores o del bedel y estacionario. Ahora me ocuparé del rector, como juez del estudio, que fue hasta 1585, cuando, a imitación de Salamanca, cedería estas prerrogativas al cancelario o maestrescuela ${ }^{40}$.

En Bolonia, la jurisdicción del rector fue menos amplia. En un primer momento, conforme a la Habita de Federico I se atribuyó a los maestros o al obispo, para defender a los escolares de los abusos de los jueces de la comuna ${ }^{41}$. Después, desde la constitución de una universitas scholarium a inicios del XIII, la ostentarían los rectores. Al parecer, en los estatutos del XIV, ejercen la jurisdicción sobre los escolares y los oftciales de la universidad en materia civil, así como en injurias leves, mientras los homicidios y las injurias atroces se reservan

\footnotetext{
39 Ordenanzas de Jaime II, citadas en nota 16. En algunos momentos intervino el monarca, por ejemplo en 1311, FiNKE, II, núm. 598, págs. 926-927. La exención de lezda en Consuetudines, núms. 3 y 57.

40 Es un capítulo de las cortes de Monzón, véase E. MUT REMOLA, «Un conflicto de competencias en el estudio general de Léridas, Miscelánea, I, págs. 129-145, en las últimas reproduce la concordia de 1606, entre el maestrescuela y tector. Véanse los estudios de J. POCH, «La bula de la maestrescolía del Estudio general de Lérida (22-agosto-1592)» y «Referencias inéditas del primer maestrescolía del Estudio general de Lérida, Dr. Matias Ferter, canónigo (15971602)n, Ilerda, 30 (1969), págs. 7-34 y 32 (1971), págs. 33-48.

41 A. MarongIU, «A propósito dell'Auth. Habita», Studi accursiani, 1988, págs. 408-421.
} 
a los jueces de la comuna ${ }^{42}$. Salamanca gozó de fuero o tribunal académico para los clérigos, en manos del obispo y del maestrescuela — con presencia de conservadores papales y regios-. A partir de 1333, el canciller o maestrescuela aparece ya como juez del estudio. Mientras, la universidad portuguesa, por estas fechas, recibía preceptos que recordaban la Habita ${ }^{43}$.

En las ordenaciones sobre Lérida de Jaime II de 2 de septiembre de 1300, ya se regulaba el tribunal del rector, delimitadas sus facultades en concurrencia con los otros que previamente existian:

Concedemos a los doctores maestros, escolates y todos los demás que dijimos, que por causa del estudio permaneciesen en dicha ciudad, sean clérigos o laicos, que en las causas civiles y también en las criminales que no llevan consigo muerte o abcisión de miembro, puedan acudir al que prefiriesen de estos tres tribunales, a saber: ante el curia de Lérida, ante el del obispo o ante el rector del mencionado estudio, excepto para el pago de los composiciones o bannos, según en el capítulo siguiente se declara ${ }^{44}$.

Y establecía algunas conductas que merecían el pago de composiciones: si se encontrasen escolares y familiates cometiendo malas acciones con atmas, clérigos o laicos, de día y dentro del recinto universitario, nada deben pagar, sólo deben de ser juzgados por sus conductas y confiscadas las armas. Si es de noche, con armas o con instrumentos musicales, pierdan unas y otros, y si son laicos, paguen la mitad de la multa que correspondería a cualquier vecino, al curia y paciarios. Si son hallados, con armas o instrumentos, fuera de los limites de sus lugares, de día o de noche, o delinquiesen, si son laicos serán juzgados como vecinos; si clérigos, nuestros oficiales les quitarán las armas y los instrumentos, pero en lo demás serían corregidos por el obispo o por el rector del estudio... Se trata de supuestos de tumultos estudiantiles, que se quieren corregir con más dureza, dando preferencia a la intervención del curia y de los paers -si bien, respecto de los clérigos se atiene a la jurisdicción episcopal o la del rector-.

En cambio, los crímenes que merecían pena corporal, quedaban fuera de esta concesión de un triple tribunal. Ya vimos que se reservaban a los cónsules

42 S. STELLING-MICHAUD, LUniversité de Bologne..., págs. 2428; las facultades jurisdiccionales del rector pueden verse en las rúbricas X y XI de los estatutos 1314-1317 de la universidad ultramontana de juristas y en X, XI, XII, LXXXVIII a LXXXXI de 1437, Statuti delle universita e dei collegi dello studio bolognese, edición de C. Malagola, Bolonia, 1888, facsímil de 1988, págs. 12 $14,53-64$ y $134-137$.

43 A. MOREIRA DE SÁ, Chartularium, doc. 25, que constituye un conjunto de privilegios del rey don Dionis en 1309 , concede la jurisdicción al obispo o su vicario y a los maestros, salvo algunos delitos que reserva a la justicia real. En Salamanca, en 1254 el obispo entendería de los clérigos y los laicos irian al justicia ordinario o alcaldes; el maestrescuela aparece muy tempranamente, en las primeras bulas, en otras posteriores de Juan XXII se alude a su jurisdicción, V. Beltrin de Heredia, Bulario, documentos 14,26 y 28 .

44 Ordenanzas citadas en nota 16. Se denominan ordenanzas u ordinaciones; en sentido estricto son un privilegio real.

Hípania, LVIII/2, nủm. 199 (1998) 515-536 
en algún momento anterior, pero ahora Ia solución eta diversa; Jaime II en abril de 1300 había alcanzado una concordia con la ciudad, para que se juzgasen por el curia — cada vez más dependiente del poder real- junto a dos paers y diez prohombres o consejeros municipales ${ }^{45}$. Este sería el tribunal en materia de alta justicia o mero imperio, como muestran las ordenaciones de Jaime II. Ya he visto con anterioridad que los que golpeasen, hiriesen o dieren muerte a algún doctor o estudiante, quedarian a la voluntad del rey, en su persona y cosas, salvo que hubiera desafiado... Y añadía que de poco sirve establecer el derecho en la ciudad, si carece de ejecución, por lo que no se debe remitir ninguna de las penas establecidas por nuestros oficiales... Y, lo que nos interesa: si alguno de estos delincuentes huyera y fuera descubierto en términos de nuestras tierras o jurisdicción, in continenti debe ser enviado a requisitoria del curia y paciarios de Lérida; si no se le capturara en tres meses, se ejecutarían en sus bienes las multas en favor del curia y paciarios, así como otras y la satisfacción de la injuria o daño.

Por tanto, el monarca distribuía la competencia entre los diversos tribunales o instancias que existian: la alta justicia, correspondería al curia y paers, como delegados del poder o jurisdicción real —los delitos que suponían muerte o mutilación de miembro -. En este plano, estarian en idéntica posición que los demás ciudadanos de Lérida. Las demás causas criminales y las civiles - la baja justicia o mixto imperio-, en Lérida, estaba asignada al curia y, en el caso de clérigos, al tribunal del obispo. Ahora quería introducir el tribunal del rector, como cabeza de la universidad, y optó por dejar la elección de los demandantes o acusadores a uno de los tres, sin atreverse a ampliar demasiado las competencias rectorales... Con algunos supuestos complementarios, que, según hemos visto, protegían a los estudiantes, con elevadas penas, cuando se les atacaba en su recinto o se les hería o mataba; también, con una especial solución en casos de tumultos escolares o jaranas con armas o con instrumentos de música... Enorme complejidad casuística, tan usual en la edad media.

¿Cómo reelaboraba estas prescripciones el Liber? Partiendo de la decisión real, que concedía al rector una posibilidad de sentenciar en los conflictos, y con algunos elementos de origen boloñés, desenvuelve y matiza las normas reales. No me refiero a la potestad disciplinaria del objeto de análisis, sino sus facultades judiciales. Veamos cómo las interpreta el Liber, como las aumenta, en relación al privilegio real.

El juicio del rector debe de ser aceptado por todos los que quieren estudiar en esta universidad. Como eres escolar o seas citado ante el tribunal del rector por otro escolar, no puedes negarte fácilmente. Lo concedido por privilegio a los estudiantes que acudan sólo al tribunal que eligiesen, se refiere si pleitean con un extraño o un ciudadano u otro que no pertenezca al cuerpo de la universidad. Entre sí y con todos los universitarios formen un cuerpo; el juicio de su rector, en cuanto cabeza de ellos y nombrado por acuerdo y voluntad de todos,

45 j. LALINDE ABADÍA, «El 'curia'...», págs. 216-217, véase mi nota 30. 
no puede ser declinado, a no ser por manifiesta y evidente sospecha u otra causa ${ }^{46}$.

Se fortalece su poder de dirimir causas y contenciones, con esta distinción entre conflictos judiciales internos - en los que evita la intervención del obispo, del curia y los prohombres - y externos, a los que se aplicaría la triple opción. Aparte los casos exceptuados por el rey, y la alta justicia o delitos atribuidos al mero imperio... Después entra en la determinación de quiénes están sujetos al juzgado rectoral, pues no quedan suficientemente nombrados en el privilegio real: «los escritores de libros, los vendedores de cartas singulares, y escolares, bedel, notario y otros semejantes, como sus familiares, que participan con nosotros en alto grado en el estudio y nosotros con ellos. Y, en general, todos los que por tazón de los estudiantes aqui moran. Los que moran sólo por el estudio y por los estudiantes, aunque no sea dentro de los límites concedidos para habitar los estudiantes, parece que realizan un oficio a ellos necesario, y están sometidos al juicio del rectons. Asimismo, aclara que los escolares de la ciudad, los médicos y artistas, que no forman parte del cuerpo universitario -en cuanto a establecer estatutos y ordenaciones o elegir al rector- están sometidos a su tribunal, incluso los maestros de gramática que enseñan a los niños en la ciudad. Procuran la mayor amplitud posible y extienden el fuero universitario al mayor número de personas u oficios, relacionados con la docencia...

El rector debería resolver conflictos sin llegar a juicio, de forma sencilla y breve, en una conciliación o en amigable composición. Podía detener a quién - de la universidad o fuera de ella- - comete delito que deba juzgarse ante su tribunal y lo metería en la cárcel del obispo o del curia, según sea clérigo o lego, quienes lo presentarían a su petición, sin ninguna dificultad o retardo. Sin embargo, en relación a los escritores que vendan las pecias o cuadernos que se les han dado a copiar o estafen en dinero a los estudiantes y luego huyeran, se pueden detener, y bien entregarlos al obispo o al curia, o bien ser entregados para su custodia al acreedor escolar, precepto que, según se afirma, sigue huellas de los demás estudios generales ${ }^{47}$.

Aunque se alegue perjuicio por sentencia del rector, no cabe apelación. Puede volverse a presentar ese perjuicio grave ante el rector y sus consiliarios, para que lo examinen de nuevo. Pero si hay un defecto de forma, en el orden procesal o por no actuar por escrito, no cabe revocación, pues es libre para actuar sumariamente y de plano, sobre los doctores, escolares y familiates... ${ }^{48}$.

He aquí como se había originado el fuero del rector, con una delegación del rey en su ámbito, ampliada y definida en el Liber, con acuerdo de los paers y del

46 Liber constitutionum et statutorum, De judiciis et foro competenti, págs. 226-227, cita en la primera; Sobre la potestad disciplinaria, De officio, et potestate rectoris, así como De vita, et honestitate scolarium, págs. 217-219, 230-231, especialmente.

47 De officio et potestate rectoris, págs. 217 y 218 , y de judiciis et foro competenti, pág. 226, quizá por ser un delito flagrante, se le retiene a pan y agua, hasta que pague; coincide con las Consuetudines, II, 60, para deudores.

48 De sentenciis et apellationibus, págs, 229-230; véanse las Consuetudines, III, 148 y 154.

Hipania, LVIII/2, nü. 199 (1998) 515-536 
obispo de Lérida. El texto de Bernardo Bonet, inspirado en Bolonia y en otros estudios generales - no, desde luego, en Toulouse- dio como resultado una amplia jurisdicción del rector... Nada sabemos de cómo se ejercería, pero, sin duda pervivió en etapas posteriores; de los primeros rectores sólo nos han quedado algunos vestigios de su potestad para establecer estatutos, juntamente con toda la universidad de juristas ilerdense ${ }^{49}$.

Queda, por último, resumir en unas breves líneas el significado de la fundación y la jurisdicción en el inicio de Lérida. El pontífice Bonifacio VIII pretendió un estudio subordinado a la iglesia, como era Toulouse surgida como consecuencia de una herejía y tutelada por los papas y los obispos; con apenas fuerza de las asambleas o congregaciones de escolares, dominadas por los doctores y por las autoridades eclesiásticas. Jaime II no quiso recorrer esta senda; desconfiaba del poder eclesial al que se vio enfrentado hasta el tratado de Agnani (1295) o como cuando creó la orden de Montesa para evitar la excesiva riqueza de otras órdenes militares, si les atribuía bienes de los extintos templarios. Y optó con sus consejeros por reproducir esquemas de Bolonia, una universitas de escolares juristas, con poderes para autogobernarse. Les concedió la elección de rectores y consiliatios, mientras él se reservaba la designación del canciller. Como no dispone de rentas, ni el pontífice se las otorga, confió el estudio general a la paeria de Lérida para que lo financiase ${ }^{50} \mathrm{y}$ nombrase sus profesores, para que lo regulara de acuerdo con el rector y escolares... De este modo, apareció la primera universidad municipal, modelo que, con los años, se implantó en la costa mediterránea: Gerona y Barcelona lo adoptaron, con mayor dependencia de sus ayuntamientos, como después Valencia o Vic. Incluso se extendería a Messina ${ }^{51}$.

El modelo de Bolonia, con una intensa presencia de la comuna, alcanzaba en Lérida una característica distinta, ya que la paeria no constituía un poder soberano como la comuna, por más que ésta estuviera en la órbita del emperador o del pontífice. Lérida estaba dominada por el municipio, bajo el poder más cercano del rey. La originaria universidad de escolares ilerdense estaba inspirada en Bolonia: autodesignación de rector y consiliarios, facultad de establecer estatutos por la universidad y jurisdicción del rector — con las variaciones que

49 Al final del Liber, la elección del segundo rector Berenguer de Sarriá, en 1 de febrero de 1302, y los estatutos que aprobó, págs. 233-234. R. GAYA MASSOT, «El 'Chariularium.», pág. 27 cita un manuscrito escurialense del XIV, en que se recogen diversos materiales, entre ellos el 12: De justitia et jure studii ilerdensis, donde se fijan las fuentes por donde debe resolver el rector: estatutos del estudio, privilegios reales, privilegios de la ciudad, leyes romanas y disposicioneș municipales.

50 Sobre su financiación, R. GAYA MASSO', «Las rentas del estudio general de Lérida», Analecta sacra tarraconensia, 25 (1952), págs. 293-338, algunas rentas eclesiales se le conceden por Benedicto XIII, págs. 314-315. También hay ayuda eclesiástica en los inicios, J. FINKE, Acta, II, doc. 589 y en el 593 se quejan de la escasa colaboración del municipio, págs. $917-918$ y 921 -922.

51 I capitoli dello Studio della nobile città de Messina, prefacio de $\mathrm{A}$. Romano, edición a cura de D. Novarese, Mesina, 1993; D. NOVARESE, Istituzioni politiche e studi di diritto fra cinque e seicento. Il Messanense Studium generale tra politica gesuita e istange egemonicbe cittadine, Milán, 1994.

Hispanaia, LVIIt/2, núm 199 (1998) 515-536 
existieran-. La estructura de poderes en Lérida, en sus inicios del 1300, aparece como una universidad escolar con toda su fuerza. Mientras en Salamanca, la deficiencia de su documentación, no permite la percepción de sus primeros tiempos, y en las constituciones de Martín V, en 1422, existe ya un equilibrio entre profesores y escolares que encubre etapas pretéritas...

Por otro lado, hemos podido comprobar la ductilidad del derecho universitario, pues Jaime II trastoca la intención del papa, al organizar con estructuras boloñesas, sin atender a Toulouse. Es más, el municipio leridano y la universidad, a su vez, readaptaron las prescripciones regias: los estatutos se deben aprobar por toda la universidad, no sólo por el rector y consiliarios, como dijo el rey; el tribunal del rector se amplia a todos los conflictos internos... Si conociésemos mejor la realidad de aquellos años - otra documentación no existe para esa época-, encontraríamos nuevas diferencias. Por ejemplo, sabemos que los tectores se limitaron desde el inicio a sólo Aragón y Cataluña... Porque el derecho y sus normas son sólo expresión de un determinado equilibrio, que las diversas fuerzas establecen en cada momento o se inclina ante las realidades. Aquí hemos podido observar algunas discrepancias o desarmonías que, en los origenes, hubo entre el papado y el rey, el municipio y la universidad... 